Erratum

\title{
Erratum to "The Characteristics and Significance of Locally Infiltrating B Cells in Lupus Nephritis and Their Association with Local BAFF Expression"
}

\author{
Chuan-Yin Sun, ${ }^{1,2}$ Yan Shen, ${ }^{1}$ Xiao-Wei Chen, ${ }^{1}$ Yu-Cheng Yan, ${ }^{3}$ Feng-Xia Wu, ${ }^{1}$ \\ Ming Dai, ${ }^{1}$ Ting Li, ${ }^{1}$ and Cheng-De Yang ${ }^{1}$ \\ ${ }^{1}$ Department of Rheumatology, Renji Hospital, Shanghai Jiaotong University School of Medicine, \\ 145 Shan Dong Zhong Road, Shanghai 200001, China \\ ${ }^{2}$ Department of Rheumatology, First Affiliated Hospital of Medical School, Zhejiang University, \\ 79 Qingchun Road, Hangzhou 310003, China \\ ${ }^{3}$ Department of Nephrology, Renji Hospital, Shanghai Jiaotong University School of Medicine, 145 Shan Dong Zhong Road, \\ Shanghai 200001, China \\ Correspondence should be addressed to Cheng-De Yang; yangchengde@hotmail.com \\ Received 19 January 2016; Accepted 16 February 2016
}

Copyright (c) 2016 Chuan-Yin Sun et al. This is an open access article distributed under the Creative Commons Attribution License, which permits unrestricted use, distribution, and reproduction in any medium, provided the original work is properly cited.

The article titled "The Characteristics and Significance of Locally Infiltrating B Cells in Lupus Nephritis and Their Association with Local BAFF Expression" [1] listed the corresponding author incorrectly. The corresponding author of this paper is supposed to be Cheng-De Yang (yangchengde@hotmail.com) rather than Yu-ChengYan. The corrected author information is presented above.

\section{References}

[1] C.-Y. Sun, Y. Shen, X.-W. Chen et al., "The characteristics and significance of locally infiltrating B cells in lupus nephritis and their association with local BAFF expression," International Journal of Rheumatology, vol. 2013, Article ID 954292, 9 pages, 2013. 


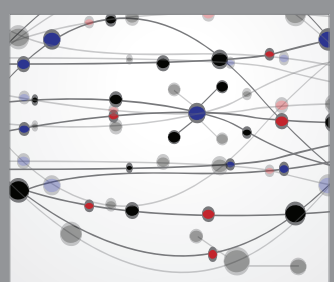

The Scientific World Journal
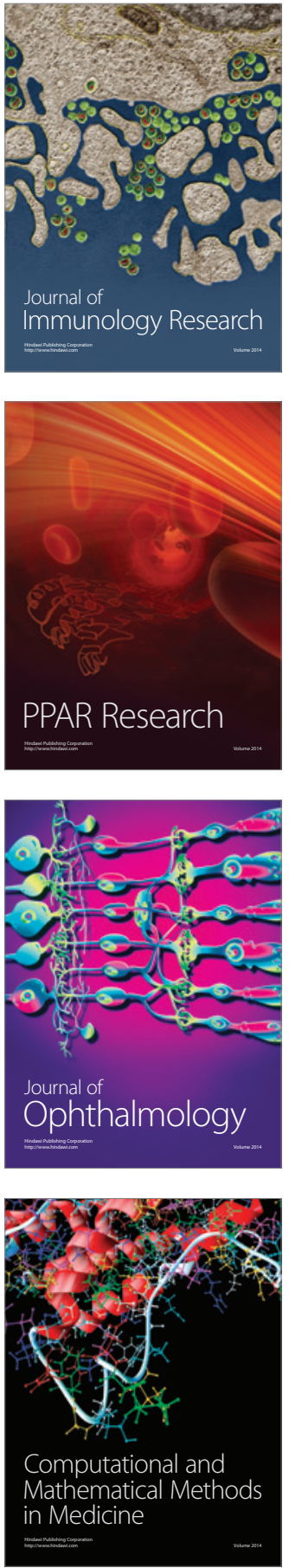

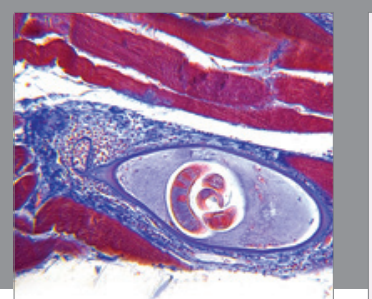

Gastroenterology Research and Practice

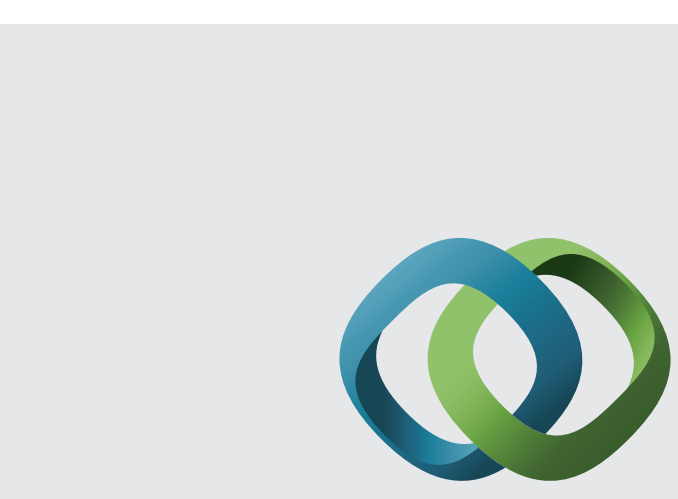

\section{Hindawi}

Submit your manuscripts at

http://www.hindawi.com
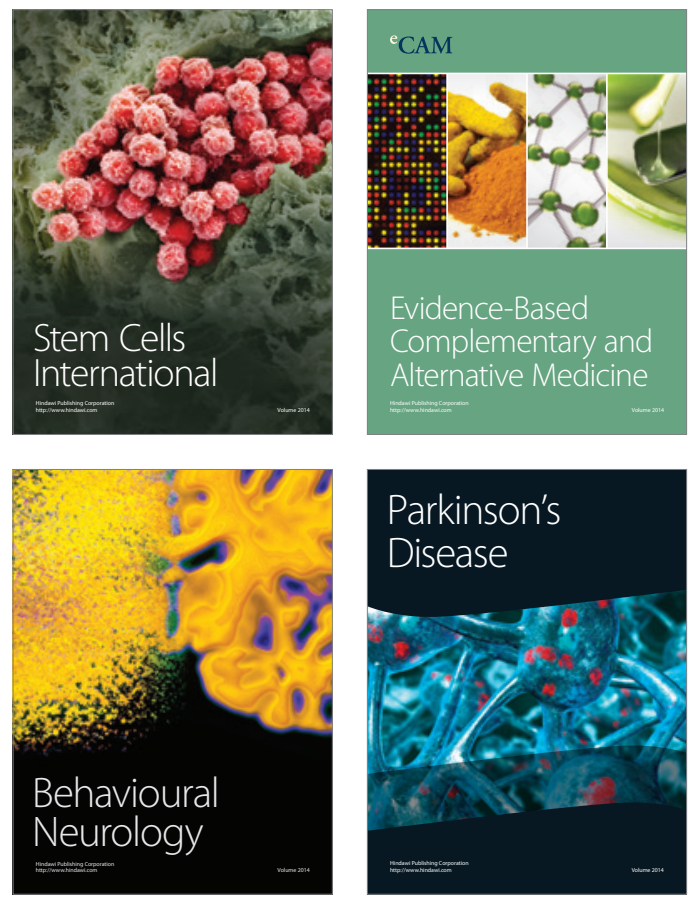
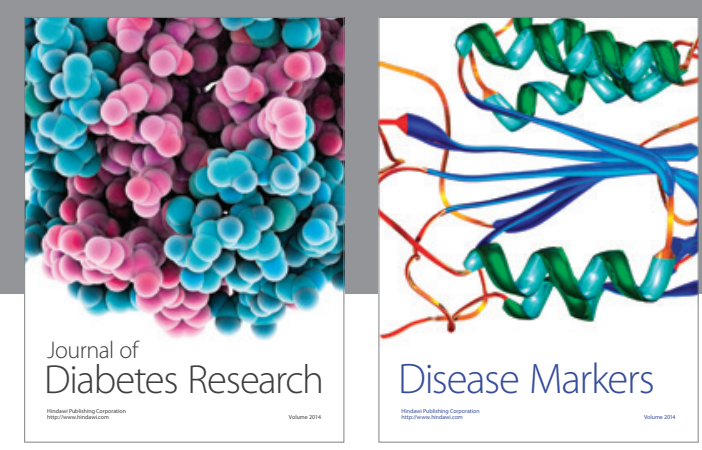

Disease Markers
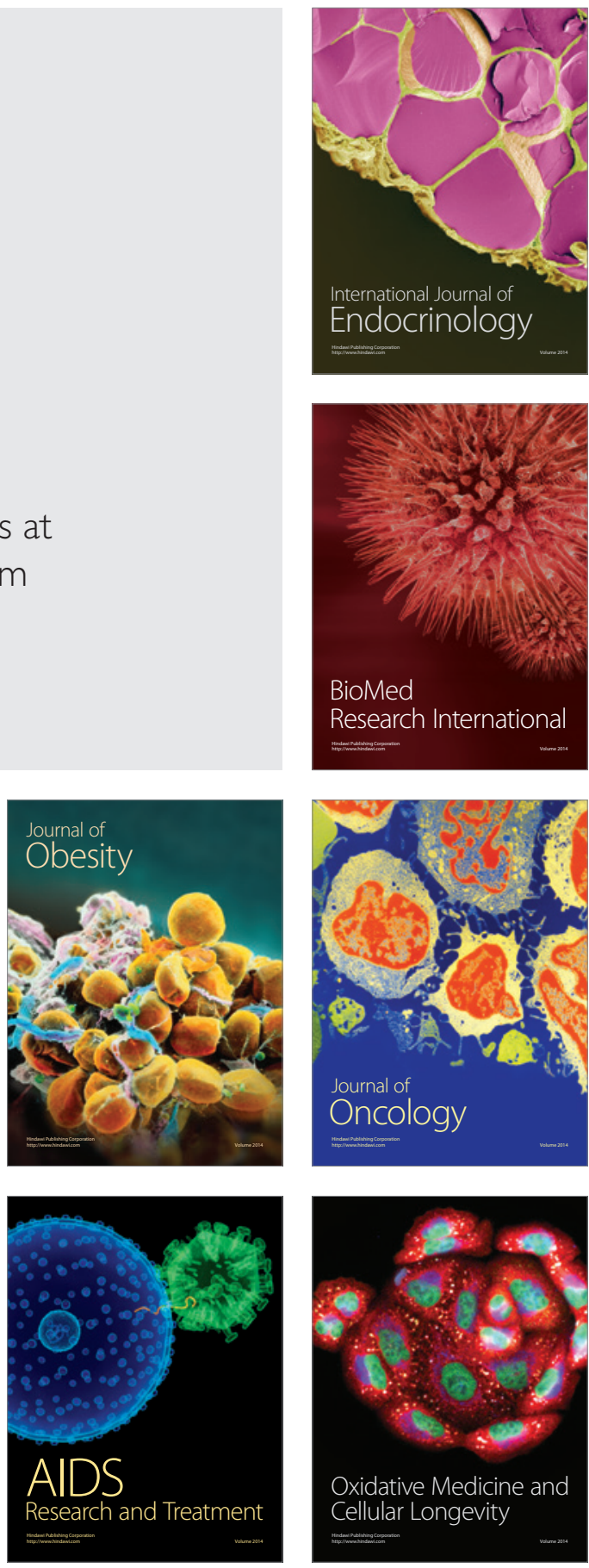